\title{
Somogy megye kerekesféreg faunájának katalógusa (Aschelminthes: Rotatoria)
}

\author{
Körmendi SÁNDOR és P. ZÁNKai Nóra
}

\begin{abstract}
KÖRMENDI S. \& P. ZÁNKAI N.: Checklist of the Rotatoria fauna of Somogy county (Aschelmintes: Rotatoria) Abstract: The study of the Rotatoria fauna started in Somogy county in 1885. So far 343 taxons have been observed in the different water bodies, 27 belonging to Bdelloidea, 270 to Ploimida and 45 to Gneisotrocha. The Rotatoria fauna of Lake Balaton is well - known, because a lot of articles have been published since 1885 . Other water bodies were much less researched in this respect. Recently studies of the Rotatoria fauna have been restarted, for example, in fishponds and in different water bodies of Duna - Dráva National Park. Discovery of new species can be expected from these investigations.
\end{abstract}

\section{Bevezetés}

Magyarországon Tóth Sándor 1861 - ben írt dolgozatában közölte az elsố Rotatoria adatokat Budapest környéki vízterek vizsgálatai alapján. Somogy megyére is vonatkozó elsó adatokat a Balaton kutatása során publikálták. A Balaton Rotatoria faunáját elóször Daday Jenó 1885 - ben vizsgálta (cit. BANCSI, 1986). P.ZÁNKAI (1968) munkájában összefoglalta az 1897 - 1957 közötti idôszak kutatási eredményeit. Elsősorban Daday. Jenó, Náday László, Entz Géza, Sebestyén Olga és Varga Lajos kutatásainak eredményeképpen 69 taxont mutattak ki a Balaton planktonjából, melyek közül tudományra nézve több új faj került elő ( $\mathrm{pl}$. Brachionus sessilis, Collotheca balatonica, Lecane balatonica stb.). A rendszeres kutatások az 1960 - as évektól folytatódtak a tihanyi MTA Balatoni Limnológiai Kutatóintézetében, ahol P. - Zánkai Nóra és Ponyi Jenố munkásságának kôszönhetốn nem csupán faunisztikai, hanem populációdinamikai, produkcióbiológiai vizsgálatok is folytak.

Somogy megye más vizes élóhelyein a balatoni kutatásokkal szemben rendszeres vizsgálatok nem folytak. Az elsó adatokat JACzó 1939 - ben Balaton melletti halastavakról közölte. Ezt követóen VARGA (1951), PONYI et al. (1973, 1974) halastavi vizsgálatain kívül csak MEGYERI (1965) Baláta - tavi vizsgálatai állnak rendelkezésre. Figyelemre méltó az is, hogy a Dráva mikrovilágáról WOYNÁROVICH (1944) vizsgálatait követően szintén csak néhány publikáció jelent meg (pl. GuLYás et al, 1995).

Somogy megye eddig vizsgált víztereiben elókerült 343 taxon $12 \%$ - a nagyon gyakori, sokféle êlőhelyen és általában nagy egyedszámban szúrhetố (a legnagyobb fajszámu a Brachionidae és Notommatidae család), 27\% - a gyakori, míg 61\% - a ritka, ennek a $61 \%$ - nak több, mint fele nagyon ritka, csak egy élóhelyen találták meg. A ritka fajok nagy aránya a kutatasok, azon belül a speciális élóhelyek (biotekton, pszammon, metafiton stb.) vizsgálatának hiányára is visszavezethető́.

A rendszeres több élóhelyre (víztípusra) kiterjesztett további vizsgálatok lényegesen növelhetik a vízterekben a fajszámot és a kvalitatív és kvantitatív vizsgálatok adatokat szolgáltatnak a víztipusok vízminôségének változásáról is. 
A Rotatoria fauna a zooplanktont alkotó állatcsoportok (egysejtúek, kerekesférgek, rákok) egyikeként egyrészt jellemzi az adott víztér vizminőségét, tápanyagellátottságát, másrészt táplálékforrást jelent a különbözô gerinctelen és gerinces (elsósorban halivadék) állatfajok számára.

A kutatások során ezért a természetes és mesterséges vízterek (Duna - Dráva Nemzeti Park: holtágak, kavicsbányatavak, égeresek, lápok: Baláta - tó stb.) biomonitoring vizsgálata mellett a halastavak termelésbiológiai állapotának vizsgálatához is rendszeres adatgyújtést kell végezni. E célból kiindulva 1996 - tól, több elốvizsgálat után elkezdődött különböző somogyi halastórendszerek kutatása is (KöRMENDI, 1996 - 2000). Eddig több Somogy megyére és halastavakra is új faj került eló (pl. Brachionus forficula, Brachionus diversicornis f. homoceros).

E dolgozatban BANCSI (Vízügyi hidrobiológia - 15, 1986; Vízügyi hidrobiológia - P7, 1988) határozókönyveiben hasznâlt rendszert és nevezéktant alkalmaztuk és a taxonokat alfabetikus sorrendben tüntettük fel.

\section{Somogy megyéből ismert fajok jegyzéke}

Adineta gracilis (Janson) $-49,58$

Adineta oculata (Milne) - 55

Adineta vaga (Davis) - 48, 58

Anuraeopsis fissa (Gosse) - 1, 12, 16, 18, 19, $20,21,22,24,25,26,27,28,29,31,33,34$,

$38,50,51,57,58,63,64$

Ascomorpha ecaudis (Perty) - 48, 49, 57, 58,

$63,64,66$

Ascomorpha saltans Bartsch - 34, 63, 64

Ascomorphella volvocicola (Plate) - 51

Aspelta cincinator (Gosse) - 48, 58

Asplanchna brightwelli Gosse - 4, 9, 19, 20,

$21,23,24,25,27,28,29,30,33,38,40,41,44,58$

Asplanchna girodi Guerne - 8, 33, 34, 37, 38,

$59,60,61$

Asplanchna herricki Guerne - 51

Asplanchna priodonta (Gosse) - 1, 3, 4, 8, 11 ,

$12,13,15,16,18,19,22,24,25,26,27,28$,

$29,34,38,41,44,57,58,60,61$

Asplanchna sieboldi (Leydig) - 3, 4, 33, 34, 38

Asplanchnopus multiceps (Schrank) - 22, 38, 66

Beauchampiella eudactylota (Gosse) - 29, 31

Bipalpus hudsoni (Imhof) - 7, 44, 58

Brachionus angularis $f$. angularis Gosse $-1,5$, $6,7,8,10,11,12,13,14,15,16,17,18,19$, $20,21,22,23,24,25,26,27,28,30,33,34$,

$37,38,44,50,57,58,59,60,61,63$

Brachionus angularis $f$. bidens (Plate) -8 ,

$9,34,44,57,58,60$

Brachionus budapestinensis f. budapestinensis

Daday - 1, 8, 16, 18, 19, 20, 21 , 22, 24, 25, 26,

$27,28,29,33,34$

Brachionus budapestinensis f. lineatus Skorikov - 9
Brachionus calyciflorus f. anuraeiformis

(Brehm) - 8, 33, 34

Brachionus calyciflorus f. amphiceros (Ehrenberg) - 8, 24, 25, 28, 29, 33, 34

Brachionus calyciflorus f. calyciflorus Pallas -1 , $5,6,7,8,10,11,12,13,14,15,16,17,18,19,20$, $21,22,23,24,25,26,27,28,30,33,34,38,58,60$

Brachionus calyciflorus $\mathrm{f}$. dorcas (Gosse) - 8, 9 ,

$24,25,28,33,34$

Brachionus calyciflorus f. spinosus (Wierzejski) $8,9,25,28,29,31,33,34$

Brachionus diversicornis f. diversicornis (Daday) - 1, 5, 8, 12, 13, 16, 17, 18, 19, 20, $21,22,23,24,25,26,27,28,29,33,34,38,60$

Brachionus diversicornis f. homoceros Wierzejski - 19, 22, 24, 25, 27,

Brachionus falcatus Zacharias - $1,5,6,8$, $9,12,13,16,18,19,20,21,22,23,24,25$, $26,27,28,29,31,34$

Brachionus forficula f. forficula Wierzejski $19,22,25,27$

Brachionus leydigi f. leydigi Cohn - 8, 16, 18, $19,20,21,22,25,26,33,34,38$

Brachionus leydigi $\mathrm{f}$. quadratus (Rousselet) - 34

Brachionus leydigi $\mathrm{f}$ rotundus Rousselet - 34

Brachionus leydigi f. tridentatus (Sernov) - 8

Brachionus plicatilis f. plicatilis O.F.Müller 33, 38

Brachionus quadridentatus f. ancylognathus (Schmarda) - 9, 33, 58

Brachionus quadridentatus f. brevispinus

(Ehrenberg) - 8, 33, 34, 58

Brachionus quadridentatus $\mathrm{f}$. cluniorbicularis

(Skorikov) - 8, 22, 25, 27, 28 


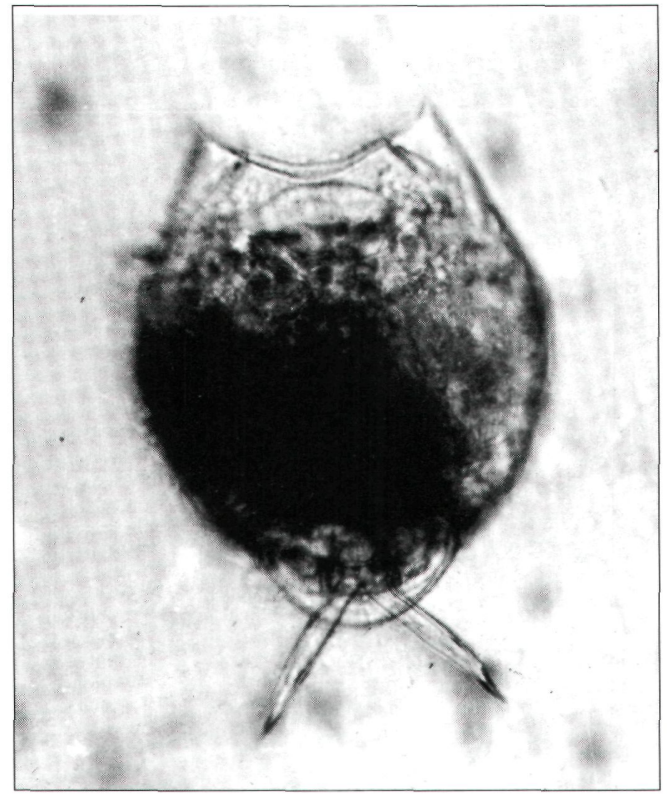

1. ábra: Lecane luna Fotó: Körmendi S.



2. ábra: Brachionus diversicornis Fotó: Körmendi S. 




3. ábra: Brachionus angularis Fotó: Körmendi S.



4. ábra: Brachionus calyciflorus Fotó: Körmendi S. 
Brachionus quadridentatus v. melheni (Barrois et Daday) - 8, 24, 28, 66

Brachionus quadridentatus v. quadridentatus Hermann - 3, 4, 7, 8, 9, 16, 18, 19, 20, 21, 22, 23, 24, 25, 26, 27, 28, 29, 31, 33, 34, 38, 48, 58 Brachionus quadridentatus v. rhenanus (Lauterborn) - 33

Brachionus rubens Ehrenberg - 8, 19, 20, 21, $22,23,24,25,27,28,33,34$

Brachionus sessilis Varga - 35, 52, 57, 58, 59,

$60,61,63,64,65$

Brachionus urceolaris f. urceolaris O.F.Müller $1,3,4,8,12,16,18,19,20,21,22,23,24$ $25,26,27,28,34,38,49,58$

Bryceella tenella (Bryce) - 47, 54, 58

Cephalodella auriculata (O.FMüller) - 47, 54, 58

Cephalodella balatonica nsp? - 66

Cephalodella biungulata (Wulfert) - 66

Cephalodella catellina (O.F.Müller) - 24, 25,

$28,47,54,57,58,59,60,66$

Cephalodella compacta Wisznievski - 47, 58

Cephalodella dentata (Wulfert) - 66

Cephalodella elongata Myers - 47, 58

Cephalodella eva (Gosse) - 54, 58

Cephalodella exigua (Gosse) - 16, 24, 25, 26,

28, 29, 47, 54, 58, 66

Cephalodella fluviatilis (Zawadowski) - 66

Cephalodella forficata (Ehrenberg) - 47, 49, 54, 66

Cephalodella forficula (Ehrenberg) - 43, 47,

$54,58,66$

Cephalodella gibba (Ehrenberg) - 8, 24, 27,

$28,29,33,47,48,54,57,58,59,66$

Cephalodella globata (Gosse) - 66

Cephalodella gobio (Wulfert) - 66

Cephalodella gracilis (Ehrenberg) - 31, 43,

$47,49,54,58$

Cephalodella hoodi (Gosse) - 58

Cephalodella limosa (Wulfert) - 66

58,66

Cephalodella megalocephala (Glascott) - 54,

Cephalodella misgurnus Wulfert - 63

Cephalodella sterea v. sterea (Gosse) - 8, 54,

$58,63,64,66$

Cephalodella tenuior (Gosse) - 47, 49, 54, 58,

63,64

Cephalodella tenuiseta (Burn) - 63

Cephalodella tinca., (Wulfert) - 66

Cephalodella ventripes (Dixon - Nuttall) - 8

$34,58,66$

Cephalodella ventripes v. angustior (Donner) - 66 Chromogaster ovalis (Bergendal) - 33, 34

Collotheca ambigua (Hudson) - 48, 58

Collotheca atrochoides Wierzejski - 58

Collotheca balatonica Varga - 35, 37, 46, 57,

58, 59, 60, 61, 63, 64, 65

Collotheca campanulata (Dobie) - 48, 58, 66
Collotheca cornuta (Dobie) - 48, 58

Collotheca coronetta (Cubitt) - 48, 58

Collotheca libera (Zacharias) - 44, 58, 63, 64

Collotheca mutabilis (Hudson) - 7, 44, 58

Collotheca ornata (Ehrenberg) - 48, 58

Collotheca pelagica (Rousselet) - 44, 58

Collotheca volutata (Sebestyen et Varga) - 39,

58,65

Collotheca volutata v. sessilis (Sebestyen) - 58

Collotheca wiszniewskii Varga - 47, 54, 58, 65

Colurella adriatica Ehrenberg - 24, 28, 29,

$31,33,38,43,44,49,54,57,58,66$

Colurella colurus f. colurus (Ehrenberg) - 3, 4,

8, 33, 34, 38, 43, 47, 54, 57, 58, 66

Colurella gastracantha (Hauer) - 47, 54, 58

Colurella obtusa f. obtusa (Gosse) - 33, 34,

38, 43, 47, 54, 58, 66

Colurella obtusa f. aperta (Hauer) - 33

Colurella paludosa Carlin - 34

Colurella tesselata (Glascott) - 48, 58

Colurella uncinata f. bicuspidata (Ehrenberg) -

47,58

Colurella uncinata f. deflexa (Ehrenberg) - 34,

51, 58, 66

Colurella uncinata f. uncinata (O.F.Müller) -

$4,5,16,18,19,20,21,24,26,28,34,43,47$,

$54,58,66$

Conochilus dossuarius v. dossuarius Hudson -

7, 40, 44, 58

Conochilus hippocrepis (Schrank) - 4, 5, 48, 58

Conochilus unicornis Rousselet - 7, 22, 23,

24, 25, 27, 28, 33, 40, 44, 48, 58, 59, 60, 61, 63, 64

Cyrtonia tuba (Ehrenberg) - 38

Dicranophorus capucinus Harring et Myers -

47,58

Dicranophorus caudatus (Ehrenberg) - 48, 58, 66

Dicranophorus epicharis (Harring et Myers) - 66

Dicranophorus forcipatus (O.F.Müller) - 8, 25,

$34,44,47,54,58$

Dicranophorus grandis (Ehrenberg) - 66

Dicranophorus hauerianus Wiszniewski - 63, 64

Dicranophorus hercules Wiszniewski - 47, 58

Dicranophorus leptodon (Wiszniewski) - 47, 58

Dicranophorus lütkeni (Bergendal) - 7, 47, 48, 58

Dicranophorus saevus (Harring et Myers) -

47,58

Dicranophorus strigosus (Harring et Myers) - 66

Dicranophorus uncinatus (Milne) - 24, 25,

$28,48,58,63,64$

Dissotrocha aculeata (Ehrenberg) - 7, 31, 34,

$48,49,58,66$

Dissotrocha hertzogi (Hauer) - 66

Dissotrocha macrostyla (Ehrenberg) - 54, 55

Elosa worallii Lord - 47, 54, 58

Encentrum felis (O.F.Müller) - 48, 58, 66

Encentrum fluviatilis (Wulfert) - 66 
Encentrum grande (Western) - 49, 58

Encentrum mustela (Milne) -34,43,54, 58, 66

Encentrum plicatum (Eyferth) - 58

Encentrum saundersiae (Hudson) - 58, 66

Encentrum wiszniewski Wulfert - 60

Enteroplea lacustris Ehrenberg - 24, 28

Eosphora najas Ehrenberg - 48, 54, 58

63, 64

Eothinia elongata (Ehrenberg) - 44, 48, 58,

Epiphanes brachionus v. brachionus (Ehrenberg) - 3, 4, 58

Epiphanes clavulata (Ehrenberg) - 20, 21, 26, 28

Epiphanes macrourus (Barrois et Daday) - 25, 33,34

Epiphanes senta (O.F.Müller) - 13, 16, 18, 19, 20,22, 24, 25, 27, 28

Erignatha clastopis (Gosse) - 48, 58

Euchlanis deflexa (Gosse) - 33, 44, 48, 58

Euchlanis dilatata f. dilatata Ehrenberg - 1, 3, $4,5,6,8,9,12,16,18,19,20,21,22,23,24$, $25,26,28,29,31,38,44,47,51,58,66$

Euchlanis dilatata f. macnura Ehrenberg - 51, 58

Euchlanis dilatata f. lucksiana (Hauer) - 33, 34

Euchlanis incisa Carlin - 38

Euchlanis lyra Hudson - 24, 28, 47, 58

Euchlanis oropha Gosse - 38, 51, 58, 66

Euchlanis parva Rousselet - 34, 49, 58

Euchlanis pyriformis Gosse - 8

Euchlanis triquetra Ehrenberg - 48, 58

Filinia cornuta v. brachiata (Rousselet) - 2

Filinia longiseta v. longiseta (Ehrenberg) - 1,

$5,6,8,12,13,16,18,19,20,21,22,23,24$,

$25,26,27,28,29,33,34,38,40,41,51,57$,

$58,59,60,61,63,64$

Filinia opoliensis (Zacharias) - 5, 6, 7, 8, 19 ,

22, 24, 25, 27, 28, 58

Filinia terminalis (Plate) - 8, 32, 58, 60, 63, 64

Floscularia conifera (Hudson) - 48, 58

Floscularia ringens (Linne) - 7, 58, 66

Habrotrocha bidens (Gosse) - 47, 58

Habrotrocha munda Bryce - 48, 58

Habrotrocha roeperi (Milne) - 48, 58

Habrotrocha tridens (Milne) - 48, 49, 58

Hexarthra mira (Hudson) - 1, 5, 6, 7, 8, 12, 16,

$18,19,20,22,24,25,26,27,28,31,33,44,58$

Itura aurita (Ehrenberg) - 34, 47, 48, 58, 66

Itura myersi Wulfert - 34

Itura viridis Stenroos - 47, 58, 66

Kellicottia longispina (Kellicott) - 3, 4, 8, 20,

$24,28,37,38,41,44,53,58,59,60,61,62$,

$63,64,65,66$

Keratella americana Carlin - 8, 38

Keratella cochlearis v. cochlearis (Gosse) - 1, 3, $4,5,6,7,8,10,11,12,13,14,16,17,18,19$,
$20,21,22,23,24,25,26,27,28,29,33,34$,

$37,41,48,49,50,57,58,60,61,63,66$

Keratella cochlearis v. hispida (Lauterborn) -

34, 44, 57, 58

Keratella cochlearis v. hispida f. pustulata

Lauterborn - 44, 58

Keratella cochlearis v. macracantha

(Lauterborn) - 24, 28, 33, 40, 44, 50, 51, 57,

$58,60,61,65,66$

Keratella cochlearis v. micracantha

(Lauterborn) - 8, 33, 34, 57, 59, 60, 61

Keratella cochlearis v. tecta (Gosse) - 1, 3, 4,

$7,8,9,16,18,19,21,22,24,25,27,28,29$,

$33,34,36,37,41,42,50,51,57,58,60,61$,

$62,63,64,66$

Keratella irregularis f. irregularis (Lauterborn) $-44,58$

Keratella quadrata v. frenzeli (Eckstein) - 44, 58 Keratella quadrata v. quadrata (O.F.Müller) -

$1,3,4,5,6,8,12,13,14,16,18,19,20,21$,

$22,23,24,25,26,27,28,29,33,34,37,40$,

$41,48,49,50,57,58,60,61,62,63,64,66$

Keratella testudo f. testudo (Ehrenberg) - 3, 4, 9, 58

Keratella ticinensis (Callerio) - 3, 4, 58

Keratella tropica f. tropica (Apstein) - 8

Keratella valga f. valga (Ehrenberg) - 3, 8,

$25,38,56,57$

Lacinularia flosculosa (O.F.Müller) - 48, 58

Lecane acus (Harring) - 31, 38

Lecane arcuata (Bryce) - 58

Lecane aspasia Myers - 48, 58

Lecane balatonica (Varga) - 47, 54, 58, 65

Lecane bulla v. bulla (Gosse) - 7, 8, 9, 22, 24,

$25,28,29,33,34,38,58,66$

Lecane clara (Bryce) - 34, 57, 63, 64

Lecane closterocerca (Schmarda) - 7, 8, 16,

$18,19,20,21,22,23,24,25,26,27,28,29$,

$31,33,34,38,47,50,51,58,66$

Lecane cornuta (O.F.Müller) - 24, 28, 29, 38 ,

47,58

Lecane elsa Hauer - 24, 28, 29, 38

Lecane flexilis (Gosse) - 43, 54, 58

Lecane gissensis (Eckstein) -43

Lecane hamata (Stokes) - 19, 22, 24, 25, 27,

$28,29,31,33,34,38,54,58,66$

Lecane inermis (Bryce) - 66

Lecane ludwigi (Eckstein) - 31, 58, 60

Lecane luna v. balatonica Varga - 58, 66

Lecane luna v. luna (O.F.Müller) - 8, 9, 19, 22,

23, 24, 25, 27, 28, 29, 31, 38, 44, 51, 57, 58, 66

Lecane luna v. presumpta Ahlstrom - 66

Lecane lunaris v. crenata (Harring) - 58

Lecane lunaris v. lunaris (Ehrenberg) - 3, 4, 8,

$24,28,29,33,34,38,43,58,66$

Lecane nana (Murray) - 24, 28, 29, 58 
Lecane obtusa (Murray) - 25

Lecane paradoxa (Steinecke) - 31

Lecane pyriformis (Daday) - 48, 58

Lecane quadridentata (Ehrenberg) - 8, 9, 19 ,

$22,24,25,27,28,29,31,34,48,51,58$

Lecane scutata Harring et Myers - 54, 58

Lecane stenroosi (Meissner) - 33, 48, 58

Lecane stichaea v. intrasinuata (Olofson) - 31

Lecane tenuiseta Harring - 54, 58

Lecane ungulata (Gosse) - 3, 8, 24, 28, 29, 48,58

Lepadella acuminata f. acuminata (Ehrenberg) -

$31,48,49,58,66$

Lepadella ovalis (O.F.Müller) - 7, 32, 33, 38,

$43,47,54,58,66$

Lepadella patella f. oblonga (Ehrenberg) - 66

Lepadella patella f. patella (O.F.Müller) - 8, 9 ,

$16,24,25,26,27,28,29,31,33,34,38,47$,

$54,57,58,66$

Lepadella patella f. similis (Lucks) - 48, 58

Lepadella quadricarinata f. quadricarinata

(Stenroos) - 38, 66

Lepadella rhomboides f. rhomboides (Gosse) -

$38,48,58,66$

Lepadella triptera (Ehrenberg) - 48, 58, 66

64

Liliferotrocha subtilis Barrios et Daday - 63 ,

Limnias ceratophyllii v. ceratophyllii Schrank -

$48,58,66$

Limnias ceratophyllii v. sphagnicola Zacharias -

48,58

Limnias melicerta Weisse - 7, 48, 58

Lindia torulosa Dujardin - 8

Lophocharis oxysternon (Gosse) - 34, 38, 58, 66

Lophocharis salpina (Ehrenberg) - 8, 29, 33,

$38,48,58,66$

Mniobia tetraodon (Ehrenberg) - 48, 58

Mniobia recurvicornis Bartos - 55

Monommata astia Myers - 48, 58

Monommata grandis (Tessin) - 48, 58

Monommata longiseta (O.F.Müller) - 24, 28,

$33,49,58,66$

Mytilina bicarinata (Perty) - 48, 58

Mytilina bisulcata (Lucks) - 31

Mytilina mucronata v. mucronata (O.F.

Müller) - 3, 29, 33, 38,44, 49, 58, 66

Mytilina mucronata v. spinigera (Ehrenberg) -

48, 58, 66

Mytilina ventralis v. brevispina (Ehrenberg) -

$8,48,58,66$

Mytilina ventralis v. macracantha (Gosse) -

31, 66

Mytilina ventralis v. ventralis (Ehrenberg) -

$24,28,29,34,44,48,57,58$

Notholca acuminata (Ehrenberg) - 3, 4, 8, 22 ,
$24,25,27,28,38,44,48,58,63,64,66$

Notholca foliacea (Ehrenberg) - 7, 44, 48, 58

Notholca intermedia (Voronkov) - 66

Notholca squamula (O.F.Müller) - 7, 8, 38,

$40,41,44,48,49,51,54,57,58,59,60,63,64$

Notholca striata (O.F.Müller) - 32, 57, 58

Notommata aurita (O.FMüller) - 25, 48, 49, 58

Notommata cerberus (Gosse) - 48, 58

Notommata contorta (Stokes) - 48, 58

Notommata copeus Ehrenberg - 3, 58, 66

Notommata cyrtopus Gosse - 49, 58, 66

Notommata pseudocerberus Beauchamp - 48,

49,58

Notommata pygmaea Harring et Myers - 48, 58

Notommata saccigera Ehrenberg - 48,58

Notommata tripus Ehrenberg - 48, 49, 58

Paradicranophorus hudsoni (Glascott) - 8, 63, 64

Philodina brevipes Murray - 55

Philodina citrina Ehrenberg - 47, 49, 54, 58, 66

Philodina erythmphthalma Ehrenberg - 3, 4, 58

Philodina flaviceps Bryce - 55

Philodina megalatrocha Ehrenberg - 3, 7, 47,

$48,49,58,66$

Philodina roseola Ehrenberg - 7, 47, 48, 49 ,

$54,58,66$

Platyias patulus f. patulus (O.F.Müller) - 22,

$24,25,27,28,31$

Platyias quadricornis $\mathrm{f}$. hexagona Wulfert - 38

Platyas quadricornis f. quadricornis

(Ehrenberg) - 19, 21, 22, 23, 24, 25, 27, 28,

$29,31,32,33,48,58$

Pleuretra brycei (Weber) - 55

Pleurotrocha petromyzon Ehrenberg - 7, 48,

58,66

Pleurotrocha robusta (Glascott) - 48, 58

Polyarthra dolichoptera (Idelson) - 7, 19, 22,

$23,24,25,27,28,29,44,58,63,64$

Polyarthra euryptera (Wierzejski) - 9, 25

Polyarthra major (Burckhardt) - 8, 51, 57,

$59,60,61$

Polyarthra minor (Voight) - 9, 29, 31, 51, 66 Polyarthra remata (Skorikov) - 24, 28, 51

Polyarthra vulgaris Carlin - 1, 3, 4, 5, 6, 8, 9,

$10,12,13,14,16,17,18,19,20,21,22,23$,

$24,25,26,27,28,29,32,33,34,36,37,40$,

$41,47,50,51,57,58,60,61,62,63,64,66$

Polyarthra vulgaris f. aptera Nipkov - 63

Polyarthra longiremis Carlin - 63

Pompholyx complanata Gosse - 3, 4, 8, 9, 16 ,

$26,40,41,49,50,57,58,60,63,64$

Pompholyx sulcata Hudson - $3,4,7,8,22$,

$24,25,27,28,33,37,40,41,44,49,50,51$,

$54,57,58,60,61,62,63,64,66$

Proales brevipes Harring et Myers - 48, 58

Proales decipiens (Ehrenberg) - 48, 49, 58, 66 
Proales fallaciosa (Wulfert) - 66

Proales micropus (Gosse) - 66

Proales minima (Montet) - 47, 54, 58

Proales similis Beauchamp - 48, 58, 63, 64

Proales theodora (Gosse) - 66

Proales werneczki (Ehrenberg) - 48, 49, 58

Proalides tentaculatus Beauchamp - 19, 22,

33, 63, 64

Ptygura brevis (Rousselet) - 48, 58

Ptygura crystallina (Ehrenberg) - 49, 58

Ptygura stygis (Gosse) - 48, 58, 66

Ptygura tihanyensis Varga - 48, 58

Rotaria citrina (Ehrenberg) - 3, 4, 7, 44, 47,

$48,49,54,58,66$

Rotaria elongata (Weber) - 48, 49, 58, 66

Rotaria macroceros (Gosse) - 48, 49, 58

Rotaria macrura (Ehrenberg) - 3, 48, 49, 58

Rotaria rotatoria (Pallas) - $3,4,7,42,47$,

$48,49,54,58,66$

Rotaria neptunia (Ehrenberg) - 8, 31

58,66

Rotaria tardigrada (Ehrenberg) - 44, 49, 54,

Rotaria tridens (Montet) - 66

Scaridium longicaudum (O.F. Müller) - 7, 25,

$31,48,49,58,66$

Sinantherina socialis (Linnaeus) - 48, 58, 66

Squatinella geleii Varga - 45, 58, 65

Squatinella longispinata (Tatem) - 48, 58

Squatinella mutica (Ehrenberg) - 38, 48, 58

Squatinella rostrum (Schmarda) - 31, 38, 66 Squatinella tridentata (Fresenius) - 24, 28,

48,58

Synchaeta kitina Rousselet - 48, 57, 58, 60,

$61,63,64$

Synchaeta longipes Gosse - 48, 58

Synchaeta oblonga Ehrenberg - 7, 8, 18, 19,

$21,22,23,24,25,26,27,28,29,37,40,44$,

$57,58,59,60,61,63,64$

Synchaeta pectinata Ehrenberg - 7, 8, 9, 16,

$18,19,20,22,23,24,25,26,27,28,29,40$,

$48,51,58,66$

Synchaeta stylata Wierzejski - 24, 28

Synchaeta tremula (O.F. Müller) - 44, 48, 57 ,

63,64

Taphrocampa annulosa Gosse - 48, 58

Testudinella caeca (Parsons) - 38

Testudinella clypeata (O.F. Müller) - 48, 58

Testudinella elliptica (Ehrenberg) - 38, 48, 58

Testudinella incisa (Ternetz) - 48, 58

Testudinella mucronata (Gosse) - 48, 57, 58, 60

Testudinella parva (Ternetz) - 8, 57

Testudinella patina f. intermedia Anderson - 66

Testudinella patine f. patina (Hermann) - 8 ,

$19,22,24,27,28,29,44,48,57,58,66$

Testudinella patina f. trilobata Anderson et
Shephard - 19, 25, 57, 66

Testudinella reflexa (Gosse) - 48, 58

Testudinella truncata (Gosse) - 48, 58, 66

Trichocerca bidens (Lucks) - 57

Trichocerca birostris (Minkiewicz) - 25

Trichocerca brachiura (Gosse) - 7, 44, 47, 48, 58,66

Trichocerca capucina (Wierzejski et

Zacharias) - 8, 19, 22, 24, 25, 27, 28, 44, 58, 60

Trichocerca cavia (Gosse) - 48, 49, 58

Trichocerca collaris (Rousselet) - 48, 58

Trichocerca cylindrica (Imhof) - 9, 24, 25, 27,

$28,48,58,66$

Trichocerca dixon - nuttalli (Jennings) - 33

Trichocerca elongata (Gosse) - 24, 28, 34, 48, 58

Trichocerca iernis (Gosse) - 48, 58

Trichocerca inermis (Linder) - 61

Trichocerca intermedia (Stenroos) - 47, 54, 58

Trichocerca longiseta (Schrank) - 7, 19, 22,

$23,24,25,27,28,29,44,58$

Trichocerca macera (Gosse) - 48, 58

Trichocerca myersi (Hauer) - 66

Trichocerca porcellus (Gosse) - 24, 28, 47, 50,

$54,58,66$

Trichocerca pusilla (Lauterborn) - 7, 8, 9, 16,

$18,19,20,21,22,23,24,25,27,28,29,34$,

$41,57,58,59,60,61,62,63,64,66$

Trichocerca rattus f. carinatus (Ehrenberg) - 3 I

Trichocerca rattus f. minor (Fadeev) - 66

Trichocerca rattus f. rattus (O.F. Müller) - 3 , $4,19,22,23,24,27,28,29,31,32,37,47$, $49,57,58,60,61,66$

Trichocerca rousseleti (Voigt) $-59,60,61,63$, 64

Trichocerca similis (Wierzejski) - 8, 40, 48, 58

Trichocerca stylata (Gosse) - 33, 44, 57, 58,

59,61

Trichocerca sulcata (Jennings) - 48, 58

Tirchocerca taurocephala (Hauer) - 44, 54, 58, 66

Trichocerca tenuior (Gosse) - 44, 47, 54, 58,

59,66

Trichocerca tigris (O.F. Müller) - 29, 31, 34,

$47,54,58,59 ; 60$

Trichocerca uncinata (Voigt) - 47, 48, 58

Trichocerca vernalis (Hauer) - 22, 24, 28, 66

Trichocerca weheri Jennings - 29, 31, 44, 49,

58,66

Trichotria pocillum f. pocillum (O.F .Müller) -

$24,25,28,38,57,58,66$

Trichotria pocillum f. bergi (Meissner) - 33, $48,58,65$

Trichotria tetractis (Ehrenberg) - 9, 31, 32, $44,48,58,63,64$

Tylotrocha monopus (Jennings) - 48, 58

Wolga spinifera (Western) - 38 


\section{Irodalom}

1. BALOGH, J. - KörMENDi S. 1983: Víztározók hidrobiológiai vizsgálata a Bikali Állami Gazdaságban. Halászat 29/76.3:67 - 71.

2. BANCSI, J. 1986: A kerekeşérgek (Rotatoria) kishatározója. I. Vízügyi Hidrobiológia 15. VIZDOK Budapest: 127.

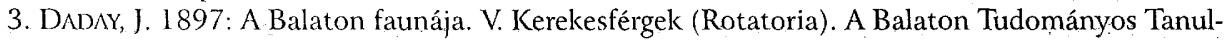
mányozásának Eredményei II. 1. Budapest: 111 - 123.

4. DADAY, J. 1897: A magyarországi tavak halainak természetes tápláléka. Magyar Természettudományi Társaság, Budapest: 1 - 481 .

5. DONÁSZY, E. 1965: A zooplankton a magyarországi halastavakban Országos mezộgazdasági Minőségvizsgáló Intézet Vízélettani Osztály, Budapest. Jelentés: l - 32.

6. DONÁSZY, E. 1966: A zooplankton a magyarországi halastavakban. Kísérletügyi Közlemények 59. B.: $71-103$.

7. ENTZ, G. - KoTTÁSZ, J. - SEBESTYÉN, O. 1937: Quantitatív tanulmányok a Balaton biosestonján. (Quantitative Untersuchungen am Bioseston des Balatons.) Magyar Biológiai Kutatóintézet Munkái 9:1 - 153.

8. GULYÁS, P. - BANCSI, I - ZSUGA, K. V. 1995: Rotatoria and Crustacea fauna of the Hungarian watercourses. Misc. Zool. Hung. 10:21 - 47.

9. JaCZó, I. 1939: Beiträge zur Kenntnis der Protozoen, Rotatorien, Copepoden und Phyllopoden einiger Fischteiche im Balatongebiet, Fragm. Faunist. Hung. 2:5 - 9.

10. KÖRMENDI, S. 1984: Béltartalom vizsgálatok pontyon (Cyprinus Carpio L.). Kutatási jelentés (D32/81) Kaposvár: $1-8$.

11. KöRMENDI, S. 1985: A zooplankton szerepe a haltenyésztésben. Szaktanácsok 3: $32-35$.

12. KörMENDI, S. 1987: A biológiai transzformációs rendszer (4D) kutatási eredményei. Halászat 6: $180-182$.

13. KöRmENDI; S. 1988: A halastavak természetes táplálékkészletének növelése és hasznosításának fejlesztése, és táplálkozásbiológiai vizsgálatok tógazdaságokban. Kutatási jelentés, (D10/88) Kaposvár: 1 - 20.

14. KÖRMENDI, S. 1989: Különböző halfajok táplálkozásbiológiai vizsgálata. Kutatási jelentés (Di 9/89) Kaposvár: 1 - 12.

15. KÖRMENDI, S. 1989: A hígfázisu mezôgazdasági melléktermékek hasznosítása zooplanktonnal. Szaktanácsok 2 - 3: 37 - 40.

16. KÖRMENDI, S. 1993: Természetes haltáplálékszervezetek kvalitatív és kvantitatív vizsgálata és testanyag összetételének analízise dél - dunántúli halastavakban. Kutatási jelentés (IP14/93) Kaposvár: 1 - 24.

17. KörmeNDI, S 1995: A hígfázisu mezőgazdasági melléktermékek hasznosítása halasított vízi rendszerekben. INTACT'95 Nemzetközi Környezetvédelmi Konferencia, Budapest: 157 - 164.

18. KörmENDI, S. 1996: A Balatoni Halászati RT Irmapusztai II. sz. tavának hidrobiológiai vizsgálata. Kutatási jelentés. Kaposvár - Balatonlelle: 1 - 15.

19. KöRMENDI, S 1997: Hidrobiológiai vizsgálatok a Balatoni Halászati RT kijelölt halastavaiban. Kutatási jelentés. Kaposvár - Siófok: 1 - 108.

20. Körmendi, S. - SZÁRI, Zs. 1997: Evaluation of an integrated duck - fish farming system at the Balaton Fishing Co Ltd. in Hungary. Problems and Solutions in Environmental Pollution, ICERTEMPUS, Baja: 43 - 60.

21. KÖRMENDI, S. 1998: Zooplankton vizsgálatok stabilizációs tó - halastó sorbakapcsolt rendszerben. Hidrológiai Közlöny 78/5 - 6:331 - 333.

22. KörmENDI, S. 1998: Hidrobiológiai vizsgálatok a Balatoni Halászati RT halastavaiban. Kutatási jelentés. Kaposvár - Siófok: 1 - 90.

23. KöRmENDI, S. 1998: Rotatoria és Crustacea vizsgálatok a Duna - Dráva Nemzeti Park különböző víztereiben. Dunándúli Dolgozatok Természettudományi Sorozat 9:37 - 43.

24. Körmendi, S. 1999: A Rotatoria (Kerekesféreg) fauna vizsgálata a Duna - Dráva Nemzeti Park víztereiben. Janus Pannonius Múzeum Term. Tud. Osztály, Pécs. Kutatási jelentés, Pécs: 1 - 18. 
25. KöRMENDI, S. 1999: Hidrobiológiai vizsgálatok a Balatoni Halászati Rt halastavaiban. Kutatási jelentés. Kaposvár - Siófok: 1 - 111.

26. KöRMENDI, S. - HANCZ, Cs. 2000: Qualitative and quantitative investigation of the zooplankton in fish ponds. Acta Agraria Kaposvariensis 4/2: $95-107$.

27. KöRMENDI, S. 2000: Hidro - , hal - és halászatbiológiai vizsgálatok a tógazdasági haltenyésztési technológia fejlesztése érdekében a Balatoni Halászati RT kijelölt halastavaiban. Kutatási zárójelentés, Kaposvár - Siófok: 1 - 30.

28.Körmend, S. 2000: Zooplankton (Crustacea:Cladocera és Copepoda és Aschelminthes:Rotatoria) vizsgálatok a DDNP különböző víztereiben 2000 - ben. Kutatási jelentés. DDNP Igazgatóság, Pécs: 1 - 35.

29. KörmeNDI, S. 2001: Zooplankton vizsgálatok a Baláta tó különböző élöhelyein. Hidrológiai Közlöny, in press.

30. KÖRMENDI, S. - SINYI, O. 2001: Hidrobiológiai vizsgálatok stabilizációs tórendszerben. Hidrológiai Közlöny, in press.

31. MEGYER, J. 1965: Adatok a Baláta - tó vízifaunájának ismeretéhez. Szegedi Tanárképző Fôisk. Tud. Közl. 2: 105 - 114.

32. NÁDAY, L. 1914: A Balaton planktonikus kerekesféreg faunája. Állattani Közlemények 13: 161 - 169.

33. PonYi, J. - Biró, P. - OlÁH, J. - P. ZÁnKAi, N. - TAMÁs, G. - CSEKeI, T. - Kiss, GY. - Morvai, T. - BANCSI, I. 1973: Limnological investigations of a fishpond supplied with sewage - water in the vicinity of Lake Balaton I. Annal. Biol. Tihany. 40: $227-284$.

34. Ponyi, J. - Biró, P. - P. Zánkal, N. - Oláh, J. - Tamás, G. - Csekei, T. - Kiss, Gy. - Morval, T. 1974: Limnological investigations of a fishpond supplied with sewage - water in the vicinity of Lake Balaton II. Annal. Biol. Tihany. 41: 235 - 288.

35. PONYI, J. 1974: A Balaton vizének élôvilága. (in Tóth, K.: Balaton monográfia) Panoráma, Budapest: $97-108$.

36. PoNYI, J. 1977: A balatoni zooplankton - kutatások újabb eredményei. Annal. Biol. Tihany. 44: $199-214$.

37. PONYI, J. 1981: A balatoni zooplankton mennyiségének és minőségének tér - és időbeli változásai és a változás okai. A Balaton kutatás újabb eredményei II. VEAB Monográfia 16, Veszprém: $11-47$.

38. RONKAY, L. 1985: Adatok a barcsi borókás kerekesféreg - faunájának ismeretéhez (Aschelminthes, Rotatoria) Dunántúli Dolgozatok (A) Természettudományi Sorozat 5, Pécs: 67 - 70.

39. SEBESTYÉN, O. - VARGA, L. 1950: Collotheca volutata n.sp. a new benthic rotifer from Lake Balaton. Annal. Biol. Tihany, 19:39 - 48.

40. SEBESTYÉN, O. - TÖRÖK, P. - VARGA, L. 1951: Mennyiségi planktontanulmányok a Balatonon I. Annal. Biol. Tihany, 20:69 - 125.

41. SEBESTYÉN, O. 1953: Mennyiségi planktontanulmányok a Balatonon II. Annal. Biol. Tihany, $21: 63: 89$.

42. SEBESTYÉN, O. 1958: Mennyiségi planktontanulmányok a Balatonon. VIII. Biomassza számítások nyíltvízi Rotatoriákon. Annal. Biol. Tihany, 25:267 - 279.

43. TÖRÖK, P. 1954: Biological investigations on waterworks supplied by spring water. Acta Biol. Acad, Sci, Hung. 5:7 - 54.

44. VARGA, L. 1932: A Balaton pelagikus Rotatoriái. Magyar Biol. Kut. Int. Munkái, 5:51 - 63.

45. VARGA, L. 1933: Squatinella geleii n.sp., egy új kerekesféreg faj hazánk faunájában. Állattani Közlemények 30: $177-186$.

46. VARGA, L. 1936: Collotheca balatonica n. sp. ein neues pelagisches Rädertier aus dem Balaton - see. Magyar Biol. Kut. Int. Munkái, P:178 - 185.

47. VARGA, L. 1938: Elózetes vizsgálatok a balatoni nedves homokpart élóvilágának (pszammon) állatairól. Magyar Biol. Kut. Int. Munkái, 10:101 - 138.

48. VARGA, L. 1939: Adatok a Balaton kerekesféreg - faunájának ismeretéhez. Az "Aszófói nádas öböl" kerekesférgei. Magyar Biol. Kut. Int. Munkái, 11:316-371.

49. VARGA, L. 1941: Adatok a Balaton part Cladophora szövedékében élő állatok ismeretéhez. Magyar Biol. Kut. Int. Munkái, 13:278 - 299.

50. VARGA, L. 1950: A halastavak életközössége és annak változásai a kaposvári Erdôgazdaság V. tógazdaságaiban. Hidrológiai Közlöny: 390 - 396. 
51. VARGA, L. 1951: A mesterséges halastósorozatok tagjainak egyedisége. MTA Biol. és Agrártud. Oszt. Közl. 1:185 - 211.

52. VARGı, L. 1951: Brachionus sessilis n. sp., új kerekesféreg faj a Balatonból. Annal. Biol. Tihany, 20:217 - 224 .

53. VARGA, L. 1954: Jégkorszaki reliktum a Balaton vízi faunájában. Annal. Biol. Tihany, 21:227 - 234.

54. VARGA, L. 1957: Újabb adatok a balatoni pszammon mikrofaunájának ismeretéhez. Annal. Biol. Tihany, 24:271 - 282.

55. VARGA, L. 1966: Kerekesférgek I. Rotatoria I. Fauna Hungariae, 7:1 - 144.

56. WoYNÁRovich, E. 1944: A Bellyei - tó, Kopácsi tó, valamint a Duna és Dráva limnológiai viszonyainak keresztmetszete. Albertina, 1. 34 - 64.

57. P. - ZÁNKAI, N. - KERTÉSZ, GY. 1967: Horizontal plankton investigatons in Lake Balaton. VI. A study of the open water Rotatoria in Lake Balaton, based on collectings in 1965. Annal Biol. Tihany, 34: $255-275$.

58. P. - ZÁNKAI, N. 1968: Über die Rädertieren - (Rotatoria) fauna des Plattensees nach literaturangaben von 1897 bis 1960. Annal. Biol. Tihany, 35:247 - 272.

59. P. - ZÁNKAI, N. - PONYI, J. 1970: The quantitative proportions of Rotifera plankton in Lake Balaton, in 1967. Annal. Biol. Tihany, 37: 291 - 308.

60. P. - ZÁNKAI, N. - PONYI, J. 1971: The horizontal distribution of Rotifera plankton in Lake Balaton. Annal. Biol. Tihany, 38:285 - 304.

61. P. - ZÁNKAI, N. - PONYI, J. 1972: Quantitative relationships of the Rotatoria plankton in Lake Balaton. Annal. Biol. Tihany, 39:189 - 204.

62. P. - ZÁNKAI, N. - PONYI, J. 1973: The biomass of Rotatoria in Lake Balaton. Annal Biol. Tihany, 40:285 - 292.

63. P. - ZÁNKAI, N. 1989: Horizontal distribution of Rotifer plankton along a trophic gradient in Lake Balaton: changes of community structure and abundance during the past 20 years. Arch. Hydrobiol. 115/1:111 - 123.

64. P. - ZÁNKAI, N. 1989: Rotatoria plankton a Balaton nyíltvizében 1984 - 85 - ben és átalakulása az utóbbi 20 évben. Állattani Közlemények, LXXV: 127 - 141.

65. P. - ZÁNKAI, N. 1990: Megemlékezés dr. Varga Lajos (1890 - 1963) a Balatonon és környékén végzett kerekesféreg - kutatásairól. Állattani Közlemények 74:105 - 108.

66. ZsUGA, K. 1996: Vizsgálatok a Balaton litorális övében élö kerekesférgeken (Rotatoria). Állattani Közlemények 81: $217-226$. 


\title{
Checklist of the Rotatoria fauna of Somogy county (Aschelmintes: Rotatoria)
}

\author{
SÁNDOR KÖRMENDI \& NÓRA P. ZÁNKAI
}

Different water bodies of Somogy county were analized and 343 taxons were determined in them. 12 percentage of all taxons were very frequent, because they were collected in different habitats and they were found in large numbers. The species of the families of Brachionidae and Notommatidae were found in the largest numbers. 27 percentage of Rotatoria taxons were frequent and 61 percentage of all taxons were rare and thin. The large ratio of rare species was due to the lack of the research of special habitats. The number of species can be significantly increased by systematical research of the different habitats and the results of the research would give more information on the changes of water quality of the different water bodies as well.

\author{
Authors'address: \\ Sándor KöRMENDI \\ University of Kaposvár \\ H - 7400 Kaposvár \\ P.O.Box 16. \\ HUNGARY \\ Dr. Nóra P. ZÁNKAI \\ Balaton Limnological Research \\ Institute of the Hungarian Academy of Sciences \\ H - 8237 Tihany \\ P.O.Box 35 . \\ HUNGARY
}

